Gut, 1986, 27, 1219-1222

Case report

\title{
Eosinophilic gastroenteritis presenting in an adolescent with isolated colonic involvement
}

\author{
D MOORE, S LICHTMAN, J LENTZ, D STRINGER AND P SHERMAN
}

From the Division of Gastroenterology, Departments of Pediatrics, Pathology, and Radiology, The Hospital for Sick Children, University of Toronto, Toronto, Ontario, Canada.

SUMMARY Eosinophilic gastroenteritis most commonly involves the stomach and proximal small intestine with eosinophilic inflammation of either the mucosa, submucosa or serosa. The patient reported here had isolated eosinophilic colitis. The initial presentation with iron deficiency anaemia owing to occult gastrointestinal blood loss emphasises the need to evaluate the entire gastrointestinal tract in patients with eosinophilic gastroenteritis.

Eosinophilic infiltration of colonic mucosa can occur as a component of the inflammatory response in Crohn's disease, idiopathic ulcerative colitis, amoebic dysentery and milk protein induced colitis. ${ }^{1}$ In addition, tissue eosinophilia develops in eosinophilic gastroenteritis which is an uncommon disorder of unknown aetiology that is typically associated with peripheral eosinophilia, abdominal pain, nausea, vomiting, and diarrhoea. ${ }^{2}$ In eosinophilic gatroenteritis mucosal infiltration of eosinophilils is most commonly limited to the antrum of the stomach and the proximal small bowel. ${ }^{3}$ We report a case of eosinophilic infiltration limited to the colon in a 17 year old boy who presented with iron deficiency anaemia.

\section{Case report}

A 17 year old white boy was referred for evaluation of iron deficiency anaemia. He complained of lethargy and reduced exercise tolerance but initially did not have gastrointestinal symptoms. There was no history of weight loss, change in appetite, and he ate a normal diet containing meat. He took aspirin infrequently for migraine headaches but had not taken any other medication. There was a past

Address for correspondence: Dr P Sherman. Division of Gastroenterology, Department of Pediatrics. The Hospital for Sick Children, 555 University Avenue. Toronto. Ontario, Canada M5G IX8

Received for publication 4 February 1986. history of infantile eczema and childhood asthma, but there was no history of specific food allergies. The family history was negative for inflammatory bowel diseases, coeliac disease and colonic polyposis.

On examination, he appeared pale but there was no evidence of jaundice, digital clubbing, or perioral pigmentation. Abdominal examination did not reveal hepatosplenomegaly, abdominal tenderness or masses and there was no evidence of perianal disease. The rectal examination was normal and leucocytes were not seen on stool microscopy. The stool was positive, however, for occult blood (Hematest tablet, Ames).

Laboratory investigations included: $\mathrm{Hb} 106 \mathrm{~g} / \mathrm{l}$, MCV $70 \mathrm{fl}$, MCHC $303 \mathrm{~g} / \mathrm{dl}$, platelets $264 \times 10^{9} / \mathrm{l}$, ESR $6 \mathrm{~mm} / \mathrm{h}$, WCC $5.8 \times 10^{9} / \mathrm{l}$, eosinophilils $0 \cdot 58 \times 10^{9} / \mathrm{l}$, serum ferritin $3.4 \mu \mathrm{g} / \mathrm{l}(16-300 \mu \mathrm{g} / \mathrm{l})$, serum iron $3 \mu \mathrm{mol} / \mathrm{l}(9-27 \mu \mathrm{mol} / \mathrm{l})$, TIBC $72 \mu \mathrm{mol} / \mathrm{l}$ (45-72 $\mu \mathrm{mol} / \mathrm{l})$, a normal haemoglobin electrophoresis, total protein $69 \mathrm{~g} / \mathrm{l}$ and albumin $42 \mathrm{~g} / \mathrm{l}$. Serum antibody titres to Yersinia enterocolitica and Entamoeba histolytica were negative. Repeated stool examinations were negative for known viral, bacterial, and parasitic enteric pathogens. Chest radiograph, electrocardiogram, and liver function tests were normal. A Schillings test with intrinsic factor was normal. Skin testing for possible allergic reactions to multiple inhalent and food antigens were negative. Serum IgE concentrations were normal. Radiologic investigations included a normal 
barium study of the oesophagus, stomach, and small bowel, and a normal ${ }^{9 \% m}$ Technetium-pertechnetate scan. Panendoscopy of the oesophagus, stomach and proximal duodenum was normal. Suction biopsies which were obtained from both the antrum and the proximal jejunum (Carey capsule, Precise Products Corp, USA) were histologically normal. After the subsequent onset of haematochezia a ${ }^{99 \mathrm{~m}} \mathrm{Tc}$ labelled red blood cell scan was carried out. ${ }^{+}$ The study indicated either blood loss or hyperaemia in the region of the transverse colon. A double contrast barium enema showed mild mucosal irregularity in the distal transverse colon (Fig. 1).

Fibreoptic colonoscopy revealed an erythematous, granular and friable mucosa with changes most marked in the transverse colon. Biopsies of colonic mucosa showed an intense inflammatory infiltrate within the lamina propria which was composed primarily of eosinophils (Fig. 2). Mast cell numbers were not increased in the lamina propria of biopsy specimens, and no microgranulomata or giant cells were identified.

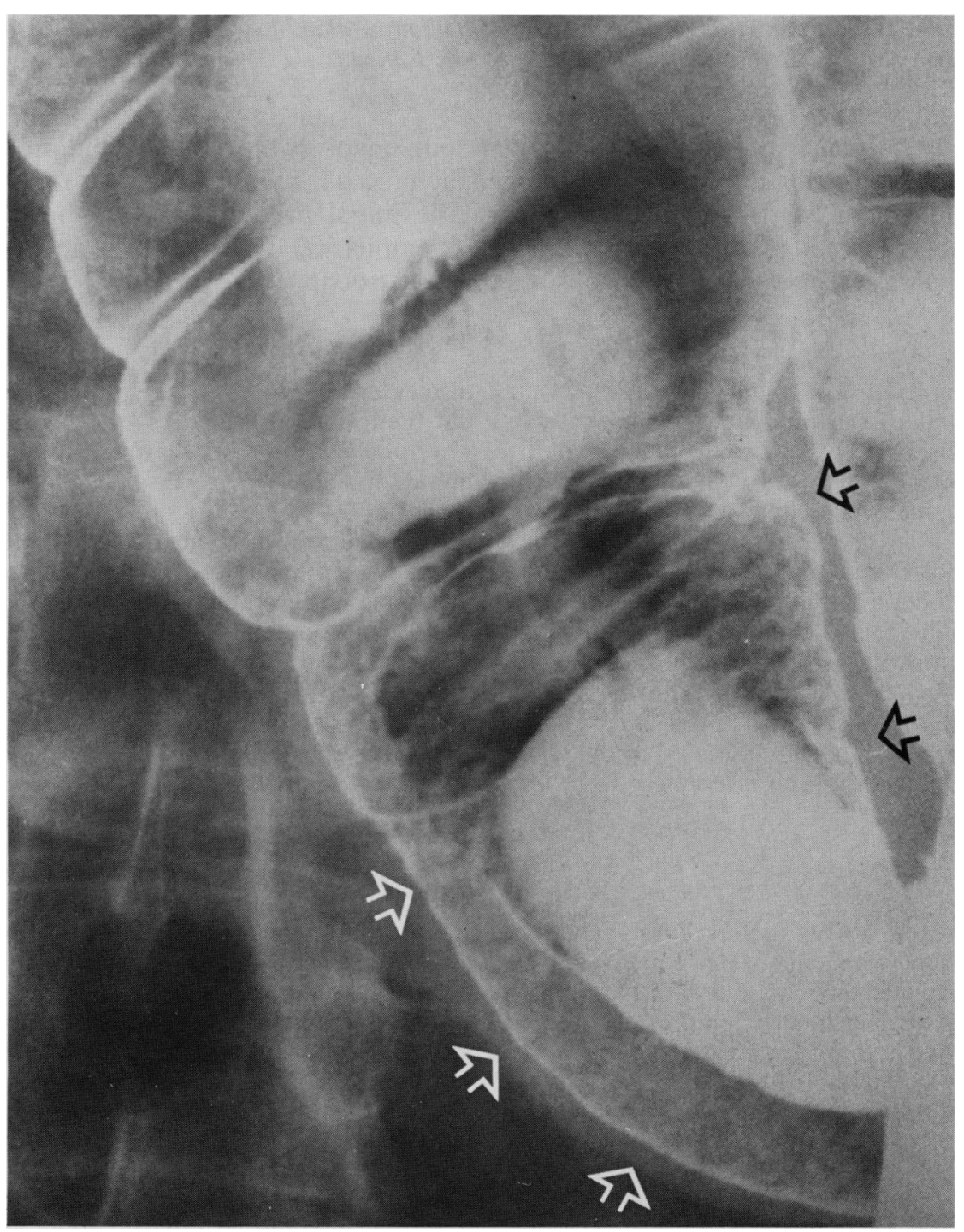

Fig. 1 Double contrast barium enema of the distal segment of transverse colon. The mucosal pattern appears irregular (arrows). 
Six weeks later the patient was on prednisone (60) $\mathrm{mg} /$ day) and was completely asymptomatic and stools were negative for occult blood. The $\mathrm{Hb}$ was $165 \mathrm{~g} / \mathrm{l}$ and the peripheral eosinophilia had resolved. After prednisone was discontinued he again developed increased stool frequency and haematochezia. Although the stools did not contain leucocytes or eosinophils (the latter evaluated after
Wright's stain), many Charcot-Leyden crystals were noted. A peripheral eosinophilia was again noted $\left(0 \cdot 88 \times 10^{9} / \mathrm{l}\right)$. Colonic biopsies revealed continued marked eosinophilic infiltration within the lamina propria.

Subsequently, he was started on ketotifen ( $2 \mathrm{mg} /$ day) with symptomatic improvement and resolution of the peripheral eosinophilia. After

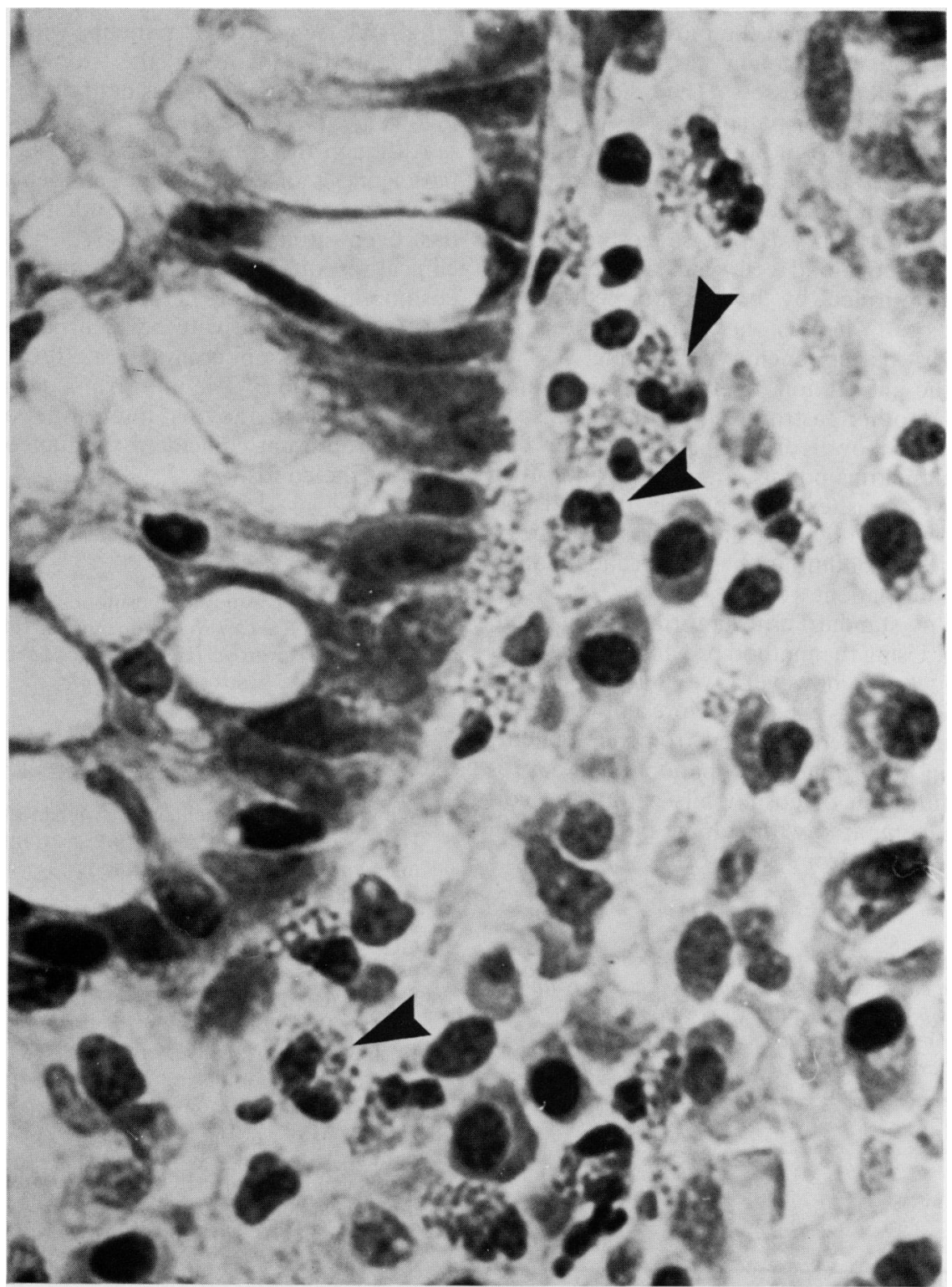

Fig. 2 Photomicrograph of a colonic biopsy which shows an inflammatory infiltrate within the lamina propria. The infiltrate consists of eosinophils which are indicated by arrowheads (haematoxylin and eosin). 
discontinuing ketotifen on two separate occasions enteric blood losses and peripheral eosinophilia were again noted which resolved after reintroduction of ketotifen.

\section{Discussion}

The unusual aspects of this case, in contrast with the more typical presentation of eosinophilic gastroenteritis, are localisation of eosinophilic infiltration exclusively in the colon and the initial presentation with iron deficiency anaemia carried by occult gastrointestinal blood losses. The diagnosis of eosinophilic colitis in our patient was based on the presence of an extensive infiltrate of eosinophils in multiple colonic biopsies in the presence of peripheral eosinophilia. Interestingly, localisation of pathology to the colon was first suggested by the ${ }^{99 \mathrm{~m}} \mathrm{Tc}$ labelled red blood cell scan. Subsequently, colitis was confirmed by both colonoscopy and colonic biopsies, whereas the changes noted on double contrast barium enema were subtle.

Eosinophilic infiltration of the gastrointestinal tract is seen in other gastrointestinal disorders such as inflammatory bowel diseases, peptic ulcer diseases, granulomatous polyps, amoebiasis and other enteroinvasive parasites, milk protein induced colitis and the systemic hypereosinophilic syndromes. ${ }^{1}$ Each of these conditions has been adequately excluded in our patient.

There are no standard criteria for assessing tissue eosinophilia. Using the method previously described by Tedesco et al, ${ }^{5}$ however, we determined the number of eosinophils which were present in colonic biopsies that had been obtained from our patient. As shown in the Table, our patient had a pronounced infiltration of eosinophils within the colonic mucosa compared with colonic biopsies which had been obtained from adolescents with Crohn's

Table Number of eosinophils per high powered field $(H P F)$ in colonic biopsy specimens, $\bar{X} \pm S D$. Numbers in parentheses indicate the range of eosinophils present within 5 HPF counted for each subject. Five separate colonic biopsies were reviewed for the patient reported

\begin{tabular}{lcc}
\hline Pathology & $n$ & Eosinophils/HPF \\
\hline Patient & 1 & $60 \cdot 8 \pm 8 \cdot 6(46-75)$ \\
Normal & 4 & $6 \cdot 3 \pm 4 \cdot 1(1-14)$ \\
Crohn's & 4 & $7 \cdot 6 \pm 6 \cdot 7(0-18)$ \\
Polyposis coli & 3 & $12 \cdot 5 \pm 8 \cdot 3(3-28)$ \\
\hline
\end{tabular}

colitis, familial polyposis coli and from teenagers with normal colonic histology. The degree of eosinophilic infiltration is the same as described by Tedesco in an adult with eosinophilic ileocolitis. Tissue eosinophil counts in colonic and rectal biopsies may prove to be a valuable method for monitoring the clinical course of such patients.

Eosinophilic gastroenteritis can affect the colon in addition to the stomach and small intestine but isolated colonic involvement appears to be quite rare. $^{6}$ We suggest that patients with eosinophilic gastroenteritis involving the stomach and small bowel should have an assessment of possible colonic involvement.

Although the role of allergic mechanisms in the pathogenesis of eosinophilic gastroenteritis is controversial, therapy with oral sodium cromoglycate has been attempted. ${ }^{78}$ We report an apparent clinical response using ketotifen in the treatment of eosinophilic colitis. Ketotifen is a benzocycloheptathiophene derivative which has been used in the place of sodium cromoglycate for the treatment of severe asthma. ${ }^{9}$ The improvement of our patient on ketotifen therapy is interesting but may, of course, represent coincident spontaneous improvement of the colitis.

\section{References}

1 Tavassoli M. Eosinophil, eosinophilia and eosinophilic disorders. CRC Crit Rev Clin Lab Sci 1981; 16: 35-83.

2 Klein NC, Hargrove RI, Sleisenger MH, Jeffries GH. Eosinophilic gastroenteritis. Medicine 1970; 49: 299-319.

3 Katz AJ, Goldman H, Grand RJ. Gastric mucosal biopsy in eosinophilic (allergic) gastroenteritis. Gastroenterology 1977; 73: 705-9.

4 Winzelberg GG, Froclich JW, McKusick KA, Strauss HW. Scintigraphic detection of gastrointestinal bleeding. A review of current methods. Am J Gastroenterol 1983; 78: 324-7.

5 Tedesco FJ, Huckaby CB, Hamby-Allen M, Ewing GC. Eosinophilic ileocolitis. Dig Dis Sci 1981; 26: 943-8.

6 Naylor AR, Pollet JE. Eosinophilic colitis. Dis Colon Rectum 1985; 28: 615-8.

7 Keshavarzian A, Saverymuttu SH, Tai PC et al. Activated eosinophils in familial eosinophilic gastroenteritis. Gastroenterology 1985; 88: 1041-9.

8 Heatley RV, Harris A, Atkinson M. Treatment of a patient with clinical features of eosinophilic gastroenteritis and polyarteritis nodosa with oral sodium cromoglycate. Dig Dis Sci 1980; 25: 470-2.

9 MacDonald GF. An overview of ketotifen. Chest 1982; 82: 303-25. 